Dept. of Animal Hygiene.

Fac. Vet. Med., Assiut University.

\title{
STUDIES ON BEHAVIORAL SEX-RELATED \\ DIFFERENCES IN THE ANXIETY LEVELS DURING PREPUBERTY, PUBERTY AND AFTER CASTRATION OR OVARIECTOMY IN RATS \\ (With 2 Figures)
}

By

\section{MADEHA DARWISH, L. KORANYY* \\ and M.A. ABDEL-RAHMAN}

* Department of Clinical and Experimental laboratory Medicine, Faculty of Health Sciences, Semmelweis University, Szabolcs u. 33-35, H-1135 Budapest, Hungary (Received at 21/5/2002)

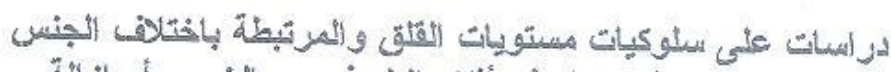

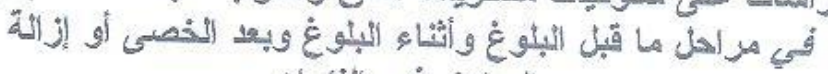
نी

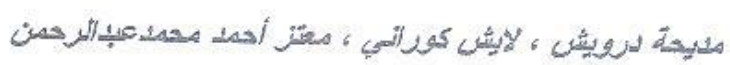

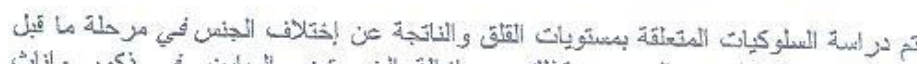

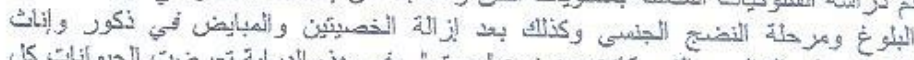

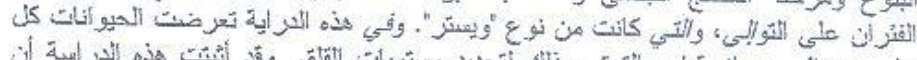

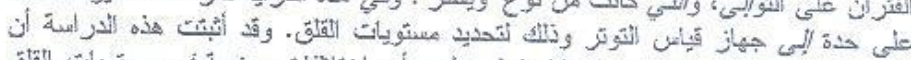

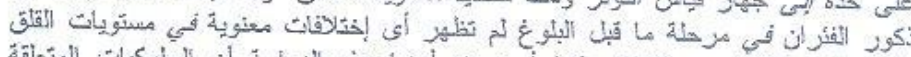

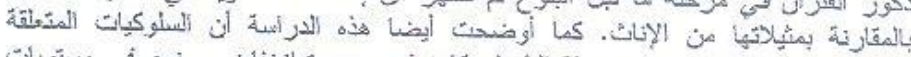

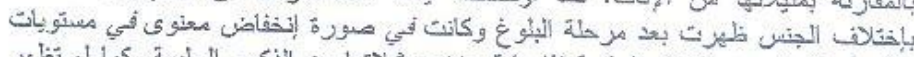

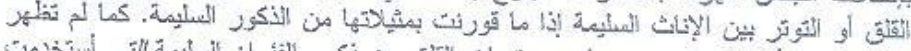

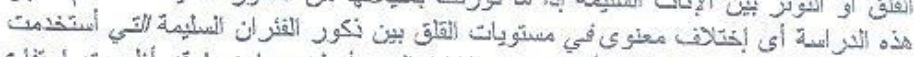

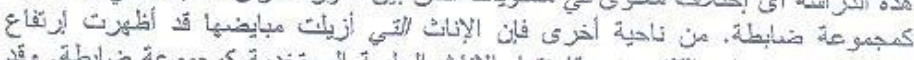

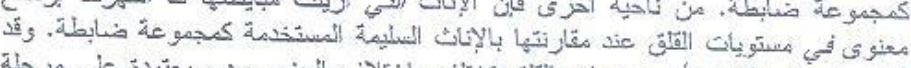

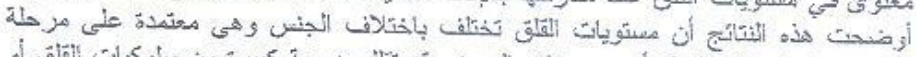

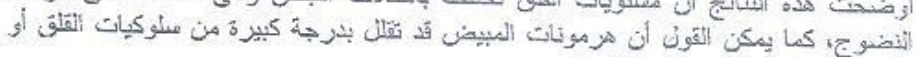

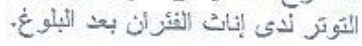




\section{SUMMARY}

Behavioral sex-related differences in the anxiety levels have been studied during prepuberty (immature), puberty (adults) and after gonadectomy of male and female Wister rats. All the animals were subjected individually to the behavioral test of anxiety in the elevated plus-maze. During prepubertal period immature malo rats showed no significant differences in their anxiety as compared to females. Behavioral sex-related differences have been detected after puberty. Intact adult female rats were significantly $(P<0.05)$ less anxious than intact adult male subjects. There were no significant differences in the anxiety levels when adult castrated males were compared to shamoperated (control) animals. On the other hand, ovartectomized female rats showed significantly $(\mathrm{P}<0.05)$ bigher anxiety levels than control subjects. These results demonstrated that sex differences in anxiety appeared to depend on puberty and suggest that ovarian hormones have damping effects on the anxiety behavior of female rats.

Keywords: Anxiety, Sex-differences, Puberty, Elevated plus-maze, Rats.

\section{INTRODUCTION}

Differences between male and female rats are found in certain brain areas involved in the organization of sexual behavior and in the hypothalamic-pituitary-adrenal axis (Hansen, 1982 and Kelly, 1991). It has been reported that in the elevated plus-maze apparatus, adult male rats showed greater aversion to the open arms, than adult female rats (Johnston and File, 1991). Moreover, adult female rats showed less emotionality than adult males indicating that adult male rats appeared more anxious than female (Zimmerberg and Farley, 1993). On the other hand, Kellog et al. (1991) and Rodgers and Cole (1993) did not find gender differences in anxiety levels in rats and mice when tested in the plus-maze apparatus.

Recently, Lucion el al. (1996) and Darwish (1998); demonstrated that adult mature female rats showed less anxiety levels than aduit males when tested in the elevated plus-maze apparatus. It will therefore be interesting to examine whether, a) male and female rats exhibit the sex differences in anxiety levels at their prepubertal period, and b) the possible role of gonadal hormones in the development of behavioral alterations in the anxiety levels after puberty (adult) period of both sexes 
in rats. The sex differences in the anxiety ieveis was measured by plusmaze apparatus,

The elevated plus-maze test was extensively validated as a model of anxiety in rats (Pellow et al., 1985 and Johnston \& File, 1991).

Therefore, the present study was designed to compare the performance of male and female rats in the elevated plus-maze before and after puberty as well as to examine the effect of castration in aduit males and ovariectomy in adult females rat on rat performance in the plus-maze, behavioral test of anxiety.

\section{MATERIALS and METHODS}

Experimental animals:

Male and female wister rats were used in the present study. Animals were maintained under standard laboratory conditions (room temperature of $22 \pm 2 \mathrm{C}$ was kept constant, $12: 12 \mathrm{~h}$ light-dark cycle was employed with light on at 6:00 a.m.). Standard laboratory food pellets and tap water were available ad libitum. All experimental procedures conformed to the laws on animal welfare. None of the rats were previously subjected to any experimental procedure. Three different experiments were performed.

\section{Experiment 1:}

Separated groups of equivalent body weight (165-180 g) of immature intact male $(N=8)$ and female $(N=8)$ Wister rats were used to test the anxiety levels in the elevated plus-maze. The rats were 30-35 days old. At this age they were sexually immature (Elwood, 1983).

\section{Experiment 2:}

This experiment was performed to measure the anxiety levels in the elevated plus maze of sexually mature males compared to those of adult mature female rats of equivalent age and body weight. Two groups ( $N=8$ rats per group) of young sexually mature ( $60-65$ days old), male and female Wister rats $(220-250 \mathrm{~g})$ were used as experimental subjects.

\section{Experiment 3:}

This experiment was designed to examine the effect of castration and ovariectomy (of adult male and female rats respectfully), on the anxiety levels as compared to that of sham-operated (control) rats. Two groups of adult males and two groups of adult females of 60-65 days old $(\mathrm{N}=8 \mathrm{rats} /$ group) were used in this experiment. 
One group of male rats was castrated while the other group was sham-operated (conirol group). Similarly, one group of females was ovarectomized and the second group was sham-operated (controls). After 30 days of surgical operations, all experimental animals (controls, castrated and ovariectomized rats) were tested individually in the elevated plus-maze apparatus.

Surgical procedures:

Castration was performed in males under ether anaethesia and the testes were removed via a midline scrotal incision. Ovaiectomy was performed in females under ether anacthesia and the ovaries were removed via a dorsolateral approach.

Sham-operated (control) male and female rats were similarly anacthized and received a surgical incisions, but neither testes not ovaries were removed.

Plus-maze apparatus:

The elevated plus-maze test has been in use as a rodent model of anxiety for a decade and is representative of those tests that are based upon the study of spontaneous behaviour patterns and which have high ethological validity (Dawson and Tricklebank, 1995 and Rodgers \& Dalvi, 1997). The elevated plus-maze test probably is the most populat of all currently available animal models of anxiety, and affords an excellent example of a model based on the study of unconditioned, or spontaneous behaviour (File, 1992; Handley \& MicBlane, 1993 and Rodgers \& Cole, 1994).

The plus-maze was described (Darwish, 2000). Briefly, a video camera was mounted vertically above the maze, and the behaviour was scored by means of a monitor and computer keyboard in an adjacent room. Each rat was placed in the central square facing the closed arm, and was allowed to explore freely the maze for $5 \mathrm{~min}$. At the end of each trial, the maze was wiped clean with a damp cloth, to remove excreta and individual odours that might have affected the behaviour of the animal. tested subsequently. The times spent in the open and closed arms were computed. The criterion for arm entry was ' 4 paws in one of the arms', while the criterion for exit was ' 2 paws out of the arm'. In addition, the percentage of time spent in the open arms was calculated [open time : (open time + closed time) $x$ 100]. By convention, an increase in the percentage of time spent in the open arms was interpreted as an anxiolytic response, whereas the number of entries into closed 
arms was taken as a measure of general activity, (e.g. anxiogenic response).

\section{Statistical analysis:}

In all illustrations of the data, mean \pm standard error of the mean (SEM) are depicted. Statistical analysis was based on raw data, and performed using a software package (SigmaStat; Jandell Scientific), Data were subjected to one-way analysis of variance (ANOVA), followed by parametric or non-parametric pairwise comparisons, depending on whether the data passed a normality test or not. The level of significance in all tests was preset at $\mathrm{p} \leq 0.05$.

\section{RESULTS}

The anxiety levels of all experimental rats were measured by two parameters in the elevated plus maze. The first parameter was the relative amount of time spent in the open arm, while the second parameter was the latency for the first entry into open arm of the plusmaze. These two parameters are interpreted as follows; increase in relative amount of time spent in the open arm and decrease in latencies reflect reduced anxiety and vice versa.

\section{Experiment 1:}

The analysis of rats behavior in the plus-maze (Fig. 1) revealed that immature males and females exhibited similar levels of anxiety. Statistical analysis of the ratio of time spent in the open arm to the total time in the plus-maze showed no significant differences between immature males and females wister rats. In addition, there were no significant differences (Fig. 2) in the latencies to first entry into an open arm of the plus-maze between immature male and female rats. These results indicate that, at the prepubertal period there were no sex differences in the anxiety levels between male and female Wister rats.

\section{Experiment 2:}

As compared to mature males, female rats showed significantly lower levels of anxiety as judged by their significant $(P<0.05)$ increased time spent in the open arm in relation to total time spent in the plus-maze as well as significant $(\mathrm{P}<0.05)$ decrease in latencies to first entry in an open arm of the plus-maze (Figs. $1 \& 2$ ). In this experiment, there were significant sex differences in the anxiety levels in adult mature rats. These results revealed that females were significantly less anxious than males. Another important finding from analysis of the data 


\section{Assiut Vet. Med.J. Vol. 47 No. 94, Jully 2002}

in Figs. 1 and 2 revealed that female rats showed a significant $(P<0.05)$ post-pubertal decrease in anxiety levels as compared to prepubertal levels. However, male rats retained their prepubertal levels after puberty.

\section{Experiment 3:}

Adult mature castrated male rats showed no significant differences in the relative amount of time spent in the open arm or in the latencies to enter an open arm of the plus-maze (Figs, 1 and 2) as compared to sham-operated (control) males. Nevertheless, adult castrated and sham-operated males showed no significant differences in their anxiety levels as compared to either immature or adult male rats. The results of this experiment clearly demonstrated that the elimination of male gonadal hormones by castration after puberty did not significantly change the anxiety levels in males as assessed in the elevated plus-maze test.

In contrast, ovariectomized female rats as compared to shamoperated animals, showed significant $(\mathrm{P}<0.05)$ increase in anxiety levels as judged by decreased in relative time spent in open arm as well as increased latencies to enter open arm of the plus-maze. This experiment also showed that the anxiety levels of ovariectomized aduil female rats were similar to those measured in females at prepubertal period. Moreover, statistical analysis of data shown in Figs. 1 and 2 showed no sionificant differences in the anxiety levels of ovariectomized female rats when compared to those observed in young immature and adult mature male rats. Sham-operated female rats showed no significant changes in their anxiety levels than those observed in adult mature females. This result indicate that elimination of ovarian hormones by ovariectomy in female rats after puberty induced significant elevation in their anxiety which become similar to those measured of male rats.

\section{DISCUSSION}

The results of the present work showed that sex differences in the anxiety levels appeared to develop after puberty. Such sex-related differences in fear and emotional behavior assessed in the elevated plusmaze showed that female rats exhibited reduced aversion for open arms, and greater amount of time spent into open arms of the maze than male rats. Because these parameters were regarded to measure anxiety in rodents (Cruz et al., 1994 and Johnston \& File, 1991), the results of the present work provide further support to the previous studies which reported that adult female rats were less anxious than males (Farabollini 


\section{Lssiut Vet. Med. J. Vol. 47 No. 94. July 2002}

et al., 1987; Zimmerberg \& Farely, 1993 and Lucion et al., 1996 \& Darwish, 1998).

It is interesting to mention that adult castrated males showed no significant differences in their anxiety as compared to sham-operated. (control) subjects. These results indicate that withdrawal of testicular hormones after puberty did not induce remarkable changes in the anxiety levels of male tats. However, ovariectomiyzed adult females displayed significantly higher levels of anxiety than intact female rats.

These finding suggest that the expression of anxiety in adult mature male rats was independent of testicular hormones, however the presence of ovarian hormones were essentially required for decreasing the anxiety levels in adult female rats.

Indeed sex-related differences have been reported in a wide variety of reproductive (De Vries et al., 1984) and non-reproductive (Beatty, 1979) behaviors. Briefly, behavioral sex-related differences believed to occur by mechanism analogous to that responsible for sexual differentiation. In rats, during the first few days (1-5 days) of the prenatal (postpartum) period, testosterone and its metabolites induce permanent alterations in the cellular structure of certain brain nuclei (medial preoptic, medial amygdala, hypothalamic paraventricular nuclei) involved in the organization of both sexual behavior and in the modulation of many aspects of non-reproductive behavior including exploration, locomotion and anxiety (Gorski et al., 1980; Kelly, 1991; Joseph et al., 1978; William et al., 1990 and Lucion et al., 1996). These steroid effects have been termed organizational effects (defeminization and masculinization), to distinguish them from the activational effects of sex steroids, which occur later throughout life (MacLusky and Naftolin, 1981). The organization effects of testosterone and its metabolites are believe to occur only during a critical period ( $1-5$ days) of the early postnatal days and produce permanent neuronal changes upon which the activational effects of testosterone can subsequently be imposed (Amold \& Breedlove, 1985; McEwan et al., 1991 and Lucion et al., 1996). Therefore, those previously mentioned reports briefly indicated that the sexually dimorphic brain nuclei were originally destined to acquire the female pattern, unless they exposed in early postnatal days (1-5 days) to testosterone or its metabolites. Furthermore, removal of testosterone at early neonatal period by castration of one day old rats resulted in a behavioral pattern that resemble the performance of female rats in the clevated plus-maze test (Gladue \& Clemens, 1982; Kelly, 1991; Lucion \& Almeida, 1991; Williams et al., 1990 and Lucion et al., 1996), On the 
other hand, castration of adult male rats (after puberty) did not lead to any remarkable alteration in the anxiety levels of the male rats as measured in the elevated plus-maze (Blizard et al., 1975; Lucion et al, 1996 and Darwish 1998). Based on the above mentioned data it could be concluded that castration at early neonatal period (1-5 days), but not after puberty might result in alterations in the anxiety levels of male rat. These findings are all consistent with our results reported in the present work.

In addition, an important finding in the present experiments was that ovariectomyzed adult female rats showed significant increase in their anxiety levels as compared to sham-operated subjects. These results suggested that gonadal hormones have an anxiolytic-like effect upon expression of anxiety assessed by elevated plus-maze. These observations are consistent with the findings which reported that female adult rats are less anxious than males (Williams et al., 1990; Becker, 1992 and Kaneko et al., 1994). Other studies have reported that ovarian hormones modulate anxiety levels, when measured in plus-maze (Mora et al., 1996 and Diaz-Veliz et al., 1997). These studies showed that ovariectomy induced highest levels of anxiogenic-like behavior, whereas administration of estradiol or progesterone was seem to induce anxiolytic effect and impair the ovariectomy-induced behavior.

In view of the above mentioned reports, it is interesting to note that young sexually immature female rats showed higher anxiety levels as compared to adult mature rats. Our tesults (experiment 1) demonstrated that young immature females exhibited significant higher levels of anxiety than adult mature rats (experiment 2 ). Therefore the present results support the suggestion that ovarian hormones modulate anxiety levels in female rats. However, further studies are required to determine which ovarian hormone (estrogen and /or progestron) is responsible for masking the expression of anxiety in female rats.

In conciusion, the present study revealed that sex-related differences in anxiety levels appeared after puberty in rats, Female rats were less anxious than males. Castrated adult male rats showed similar levels of anxiety as those observed in intact control subjects. On the other hard ovariectomized female rats displayed higher levels of anxiety as compared to sham-operated (controi) subjects.

\section{REFERENCES}

Arnold A.P. and Breedlove S.M. (1985): Organizational and activational effects of sex steroids on brain and behaviour: a re-analysis. Horm. Behav, 19: 469-498. 
Beatty, W.W. (1979): Gonadal hormones and sex differences in nonreproductive behaviors in rodents: organizational and activitional influences. Horm. Behav, 12: 112-163.

Becker J.B. (1992): Hormonal influences on extrapyramidal sensorimotor function and hippocampal plasticity. In: Becker J. B, Breedlove S.M, Crews D. ed. Behav. Endocrinol. Massachusetts: MIT Press 325-356.

Blizard, D.A.; Lippman, II.R., and Chen J.J. (1975): Sex differences in open-field behavior in the rat: the inductive and activational role of gonadal hormones. Physiol. Behav. 14: 601-608.

Cruz A.P.M.; Frei F. and Graeff F.G. (1994): Ethopharmacological analysis of rat behaviour on the elevated plus-maze. Pharmaco. Biochem. Behav, 49: 171-176.

Darwish, M. (1998): Steroid hormone control of maternal behavior and the endocrine response to stress in rat. $\mathrm{Ph}$. D. Thesis, Fac. Vet.Med. Assiut University.

Darwish, M. (2000): Maternal deprivation of neonatal rats increased anxiety levels and pituitary-adrenal activity of preweanling and young rats.Assiut Vet. Med. J. 43,86: 129-146.

Dawson, G.R. and Tricklebank M.D. (1995). Use of the elevated plus maze in the search for novel anxiolytic drugs. Trends Pharmacol. Sci. 16:33-36.

De Vries, G.J.; Brain, J.P.C.; Uylings, H.B.M and, Corner, M.A. (eds) (1984): Sex differences in the brain. Prog. Brain Res., 61: 516.

Díaz-Véliz G.; Alarcón, Espinoza, C.; Dussaubat, N. and Mora, S. (1997): Ketanserin and anxiety levels: Influence of gender, estrous cycle, ovariectomy and ovarian hormones in female rats. Pharmacol. Biochem. Behav. 58: 637-642.

Elwood, R.W. (1983): Parental behaviour of rodents. John Willy \& sons, New York. Farabollini F, File S.E, Johnston A.L, Wilson C.A. (1987): An analysis of sex differences in the open field and tests of exploration and anxiety. Br.J. Pharmacol. 90:263P.

File, S.E. (1992). Behavioural detection of anxiolytic action. In: Elliott J.M, Heal D.J, Marsden C.A. eds. Experimental approaches to anxicty and depression. New York: John Wiley \& Sons Ltd: 25 44. 
Gorskt, R.A.; Harlan, R.E.; Jacobson, C.D.; Shryne, J.E. and Southam, A.M. (1980): Evidence for the existence of a sexually dimorphic nuclus in the preoptic area of the rat. J. Comp. Neurol. 193: $529-539$.

Handley, S. and McBlana, J.W. (1993). An assessment of the elevated $\mathrm{X}$-maze for studying anxiety and anxiety-modulating drugs.. . Pharmacol. Toxicol. Meth. 29: 129-138.

Hansen, S. (1982): Hypothalamic control of motivation: the medical preoptic area and masculine sexual behavior of the rat. Scand $J$. Psychol. 1: 121-126.

Johnston, A.L. and File, S.E. (1991): Sex differences in animal test of anxiety. Physiol. Behay. 49:245-250.

Joseph, R.: Hess, S. and Birecree, E. (1978): Effects of hormone manipulations and exploration on sex differences in maze learning. Behav. Biol. 24: 364-377.

Kaneko, W.; Riley, E.P and Ehlers, C.L. (1994); Behavioural and electrophysiological effects of early repeated maternal separation. Depression 2: 43-53.

Kellog, C.K.; Primus, R.J. and, Bitran D.: (1991): Sexually dimorphic influence of prenatal exposure to diazepam on behavioral response to environmental challenge and on gama-aminobutyric acid (GABA)-stimulated chloride uptake in the brain. J. Pharmacol. Exp. Ther.256: 259-265.

Kelly, D. (1991): Sexual differentiation of the nervous system. In: Kandel, E. Schwartz J.H. Jessell T.M. ed. Principles of Neural Sciences. New York: Elsevier: 959-973.

Lucion, A.B. and de Almeida, R.M.M. (1991): Role of intruder in the aggressive behavior of colonies of wild rats (Rattus norvegicus). In: Olivier, B., Mos, J., Slangen J.L., ed. Animal models in psychopharmacology. Basal: Birkhauser; 347-356.

Lucion, A.B.; Charchat, H.; Gabriel, A.M. and Rasia-Filho, A.A. (1996): Influence of early postnatal gonadal hormones on anxiety in adult male rats.Physiol. Behav. 6: 1419-1423.

Maclusky, N.J. and Nofiolin, F. (1981): Sexual defferentiation of the centrail nervous system. Science 211: 1294-1303.

McEwen B.S.; Coirini, H.; Westlind-Danielssn, A.; Frakfurt, M.; Gould, E.; Schumacher, M. and Wooley, C. (1991): Steroid hormones as mediators of neural plasticity. J. Steroid Biochem. 39: 223232. 
as mediators of neural plasticity. J. Steroid Biochem. 39: 223232.

Mora, S.; Dussaubat, N. and Diaz-Veli, G. (1996): Effects of the estrous cycle and ovarian hormones on behavioural indices of anxiety in femaie rats. Psychoneuroendocrinol.: 609-620.

Pellow, S.; Chopin, P.; File, S.E. and Briley, M. (1985): Validation of opentclosed arm entries in an elevated plus-maze as a measure of anxiety in rat. J. Neurosci. Methods 14: 149-167.

Rodgers, R.J. and Cole, J.C. (1993): Influence of social isolation, gender, strain and prior novelty on plus-maze behavior in mice. Phys. Behav, 54: 729-736.

Rodgers, R.J. and Cole, J.C. (1994). The elevated plus-maze: pharmacology, methodology and ethology. In: Cooper S.J, Hendric C.A. eds. Ethology and psychopharmacology. 9-44. Chichester Wiley.

Rodgers, R.J. and Dalvi, A. (1997). Anxiety, defence and the elevated plus-maze. Neurosci. Biobehav. Rev. 21: 801-810.

Williams, C.L.; Barnett, A.L. and Meck, W.H. (1990): Organizational effects of early gonadal secretios on sexual differentiation in spatial memory. Behav. Neurosci. 104: 84-97.

Zimmerberg, B. and Farley, M.J. (1993): Sex differences in anxiety behavior in rats: role of gonadal hormones. Physiol. Behav. 54: 1119-1124.

\section{LEGENDS,}

Fig. 1: Showing the percentage of time spent into open arms (The time spent into open arms in relation to total time spent in both open and closed arms of the plus-maze), for immature and mature rats as well as castrated and ovarectomized animals.

Asterisk indicates statistically significant differences $(\mathrm{P}<0.05)$ per animal groups within each experiment. Asterisk indicate significant differences $(P<0.05)$ as compared to male rats, \# sign denotes significant differences $(p<0.05)$ due to effect of ovariectomy.

Fig. 2: Showing Iatencies to first entry into open arms of the plus-maze for immature and mature rats as well as castrated and ovariectomized animals. Asterisk indicates statistically significant differences $(\mathrm{P}<0.05)$ as compared to male rats. \# sign indicates significant difference $(\mathrm{P}<0.05)$ due to effect of ovariectomy. 


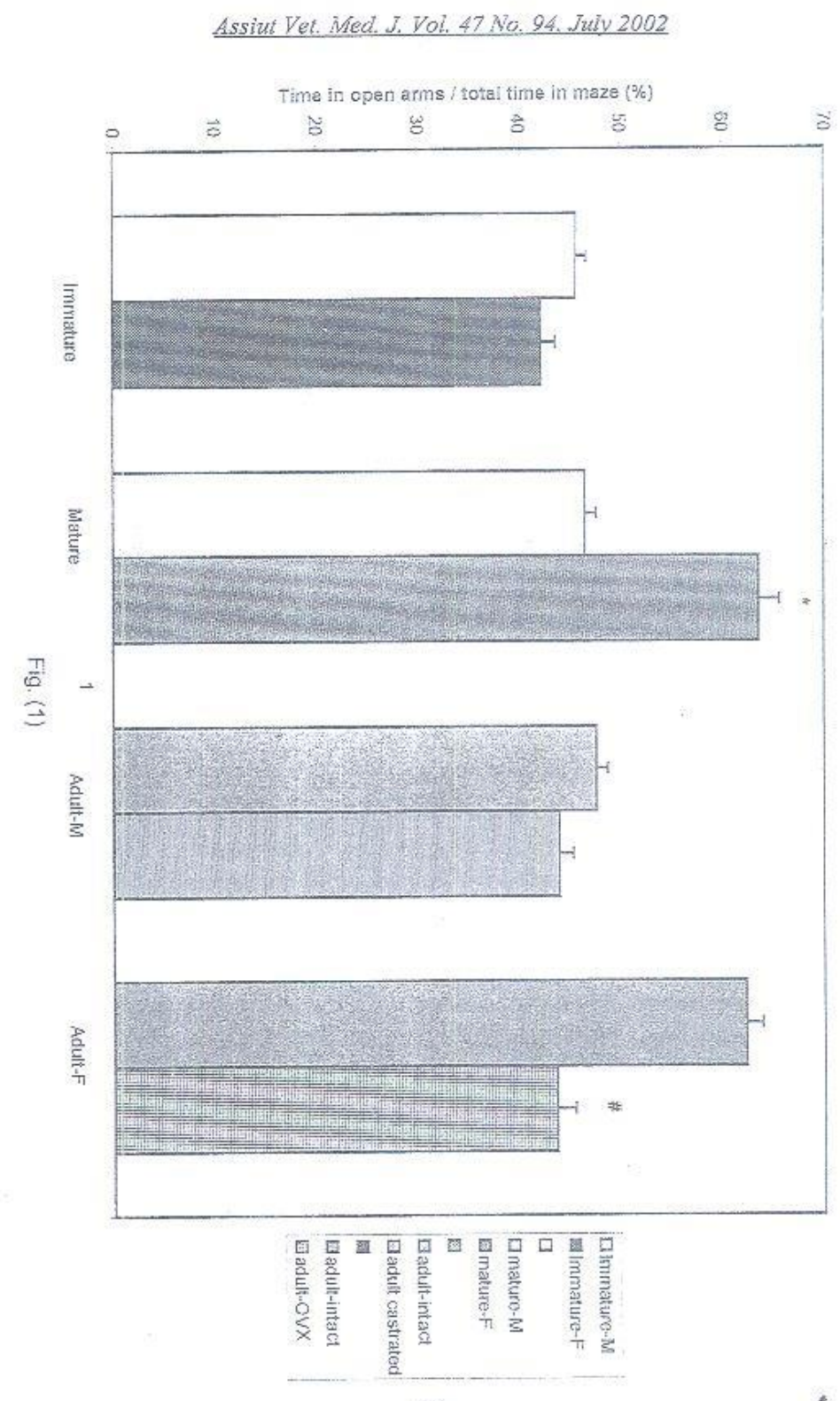




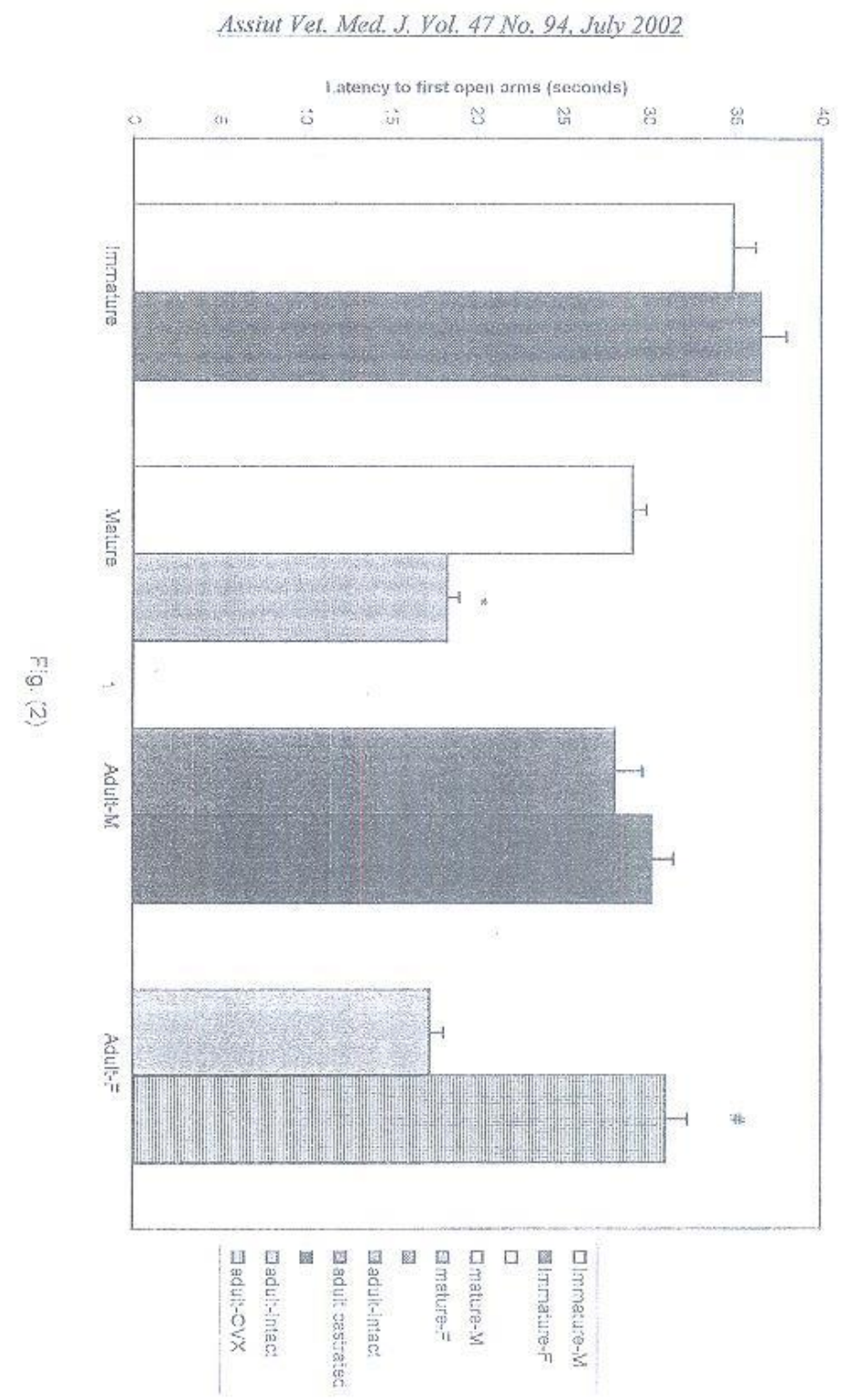

